\title{
Testing the aversiveness of a stimulus by a response-transfer procedure
}

\author{
HARRY M. B. HURWITZ \\ University of Guelph, Guelph, Ontario NIG 2Wl, Canada \\ and \\ ROBERT JORDAN \\ Warren Wilson College, Swannanoa, North Carolina 28778
}

\begin{abstract}
The aversiveness ot tones of $86 \mathrm{~dB}$ and $118 \mathrm{~dB}$ for six rat subjects was tested in a design that first trained each subject to escape from shock by pressing a lever. When tone was substituted for shock, no major transfer of the escape response was found with the 86-dB tone; there was an effect when the higher intensity tone, $118 \mathrm{~dB}$, was used, but the effect was erratic.
\end{abstract}

In a conditioning experiment, two functional properties of a stimulus are assumed: the control of the stimulus over behavior prior to conditioning (i.e., the unconditioned stimulus-response relation) and the control of the stimulus over behavior after the procedure has been imposed (i.e., the conditional stimulus-response relation). Unconditioned and conditioned response have often been classified according to whether they mediate approach toward an object or result in withdrawal or flight. A stimulus that controls withdrawal or flight is viewed as having aversive properties, one that controls approach, an appetitive function. The resultant fourfold classification for stimuli, and for the responses they control, raises the problem whether conditioning is facilitated or impeded by a combination of stimuli that initially control opposing responses.

The present experiment limits itself to the question of whether different intensities of tone control withdrawal/ flight responses. In earlier experiments, we used such tones to signal the imminent presentation of a mild but aversive shock (Hurwitz \& Roberts, 1977). During presentation of the tone, previously conditioned avoidance behavior was disrupted, even suspended. As a result, subjects received many more shocks during the tone than prior to the presentation of the warning signal. Was this effect entirely due to the conditioning of the tone to shock or was some of the effect attributable to the tone itself? That is, could the tone be classified as aversive in its own right? The strategy adopted to answer this question is somewhat unusual. The subjects were first trained to cope with a reliable aversive stimulus, namely, shock: They were given extensive training in escaping from shock by pressing a lever. Subsequently, tones of different intensities were substituted for shock on the assumption that the previously learned escape response would transfer if the tone belonged to the class of unconditioned aversive stimuli.

\section{METHOD}

\section{Subjects}

The subjects were six female hooded rats obtained from Blue
Spruce Farms, New Jersey. They were approximately 120 days old and weighed between 175 and $200 \mathrm{~g}$. Each subject was housed in an individual cage, with food and water always available.

\section{Apparatus}

A single Lehigh Valley operant chamber was used. The chamber was placed in a large sound-resistant container that stood in a sound-insulated room. The chamber measured $23 \times 24 \times 24 \mathrm{~cm}$ and was equipped with a 5-cm-wide lever that protruded $2.5 \mathrm{~cm}$ into the chamber $5 \mathrm{~cm}$ above a grid floor. A weight of $10 \mathrm{~g}(.01 \mathrm{~N})$ was needed to depress the lever. The grid consisted of $.25-\mathrm{cm}$ brass rods spaced $1.3 \mathrm{~m}$ apart and was parallel to the lever. A constant-current shock generator delivered shock via a scrambling device to the rods, the lever, and the sides of the chamber. The shock generator delivered $.8 \mathrm{~mA}, 170 \mathrm{~V} \mathrm{dc}$.

A $4,000-\mathrm{Hz}$ Malloy Sonalert was positioned above the lever and delivered either $86 \mathrm{~dB}$ or $118 \mathrm{~dB}$ when activated. Lever responses were recorded on counters set up to identify all responses that occurred within $2 \mathrm{sec}$ of the presentation of shock or of tone. Both shock and tone were delivered for $10 \mathrm{sec}$ unless terminated by a response on the lever.

\section{Procedure}

A summary of the procedures is given in Table 1 . Fourteen sessions were run, divided into a block of six sessions during which 25 shocks were presented per session and a block of eight sessions during which 50 shocks, 50 tones, or 50 tones associated with shock were presented. During each session, shock, tone, or both were administered once every $15 \mathrm{sec}$ for $10 \mathrm{sec}$ unless terminated by response. Thus every cycle from the onset of the shock, tone, or both was $25 \mathrm{sec}$ long. A response in the presence of shock or tone terminated the stimulus; a response made during the interstimulus interval had no consequence. Session 7 was the first on which 50 cycles were given; shock was omitted and, instead, a tone of $86 \mathrm{~dB}$ was substituted. As previously, a

Table 1

Design

\section{Session}

16 Shock-escape training. All six subjects. 25 trials/session.

$7 \quad$ Escape from $86-\mathrm{dB}$ tone. 50 trials.

8 Shock escape as in Sessions 16.

9 Escape from $118 \mathrm{~dB}$ : Subjects 4, 5, 6. Continued with shock: Subjects $1,2,3$.

10-11 Escape from shock and tone simultaneously presented.

12 Escape from $86 \mathrm{~dB}$ : Subjects 1, 2, 3.

Shock escape: Subjects $4,5,6$.

13 86-dB escape possible. All subjects.

$14 \quad 118-\mathrm{dB}$ tone escape. All subjects. 
Table 2

Sessions

\begin{tabular}{|c|c|c|c|c|c|c|c|c|c|c|c|c|c|c|}
\hline \multirow[b]{3}{*}{ Subject } & \multicolumn{14}{|c|}{ Session } \\
\hline & \multicolumn{6}{|c|}{ Shock Escape } & \multirow{2}{*}{$\frac{86 \mathrm{~dB}}{7}$} & \multicolumn{4}{|c|}{ Shock Tone Escape } & \multicolumn{2}{|c|}{$86 \mathrm{~dB}$} & \multirow{2}{*}{$\frac{118 \mathrm{~dB}}{14}$} \\
\hline & 1 & 2 & 3 & 4 & 5 & 6 & & 8 & 9 & 10 & 11 & 12 & 13 & \\
\hline $\begin{array}{l}1 \\
2 \\
3 \\
4 \\
5 \\
6\end{array}$ & $\begin{array}{l}30 \\
57 \\
67 \\
56 \\
39 \\
56\end{array}$ & $\begin{array}{l}56 \\
68 \\
73 \\
75 \\
89 \\
50\end{array}$ & $\begin{array}{l}73 \\
36 \\
42 \\
94 \\
71 \\
66\end{array}$ & $\begin{array}{l}34 \\
65 \\
73 \\
84 \\
96 \\
70\end{array}$ & $\begin{array}{l}68 \\
81 \\
79 \\
92 \\
88 \\
72\end{array}$ & $\begin{array}{l}46 \\
88 \\
90 \\
96 \\
92 \\
78\end{array}$ & $\begin{array}{l}0 \\
0 \\
0 \\
0 \\
0 \\
0\end{array}$ & $\begin{array}{l}64 \\
88 \\
98 \\
90 \\
90 \\
86\end{array}$ & $\begin{array}{r}57 \\
91 \\
100 \\
15 \\
14 \\
10\end{array}$ & $\begin{array}{l}75 \\
94 \\
96 \\
92 \\
94 \\
93\end{array}$ & $\begin{array}{l}90 \\
89 \\
94 \\
98 \\
98 \\
90\end{array}$ & $\begin{array}{r}1 \\
2 \\
6 \\
99 \\
98 \\
90\end{array}$ & $\begin{array}{l}0 \\
0 \\
0 \\
0 \\
0 \\
0\end{array}$ & $\begin{array}{r}5 \\
46 \\
56 \\
26 \\
20 \\
18\end{array}$ \\
\hline Mean Percent & 50.8 & 66.6 & 63.6 & 70.3 & 80.0 & 81.6 & 0 & 86.0 & 82.6 & 90.6 & 93.1 & 95.6 & 0 & 28.5 \\
\hline
\end{tabular}

Note-The results are represented for each subject in terms of the percent of trials on each session in which an escape response occurred within 2 sec after shock or tone onset. In Sessions 9 and 12, some subjects (italicized entries) continued under shock escape.

response during the tone terminated this stimulus. On Session 8 , shock was reinstated. On Session 9, Subjects 1, 2, and 3 were presented shock and tone, whereas Subjects 4,5 , and 6 were exposed only to a 118-dB tone. On Sessions 10 and 11 all subjects were given shock-tone. On Sessions 12 and 13, Subjects 1,2 , and 3 were presented the $86-\mathrm{dB}$ tone only; Subjects 4 , 5 , and 6 continued with shock-tone during Session 12 and were then switched to an $86-\mathrm{dB}$ tone on Session 13. Finally, on Session 14 all six subjects were presented the 118 -dB tone only.

\section{RESULTS}

The data are presented in Table 2 in terms of the percent trials on which an escape response occurred within $2 \mathrm{sec}$ of the onset of the stimulus (shock or tone or both). The results show that within relatively few sessions most subjects learned to escape shock within $2 \mathrm{sec}$. Only Subject 1 remained a slow responder. No subject escaped within $2 \mathrm{sec}$ to a low-intensity tone (i.e., $86 \mathrm{~dB}$ ) before the tone and shock had been paired. Even after pairing (Session 12, Subjects 1, 2, and 3 ), very few escape responses were recorded that met the 2-sec latency criterion. A different picture emerged when the tone intensity was raised to $118 \mathrm{~dB}$ : On Session 9 Subjects 4, 5, and 6 made several escape responses, and on Session 14, when all subjects were exposed to the intense tone, several subjects responded quite frequently to the onset of tone within $2 \mathrm{sec}$.

\section{CONCLUSIONS}

Myers $(1959,1965,1967)$ first reported that responses that could terminate a $4,000-\mathrm{Hz} 105-\mathrm{dB}$ pure tone were not differentially strengthened, but that white noise would be escaped. It is conceivable that the failure to demonstrate that such an intense tone was aversive was due to the fact that the required response was not readily available to the subjects. Had subjects been pretrained in the situation, they might have terminated the tone. The present experiment lends some support to this interpretation. Clearly, a tone of $86 \mathrm{~dB}$ was insufficiently aversive, since it was not escaped. Even when the criterion was changed beyond $2 \mathrm{sec}$ after onset of the stimulus, there was no substantial difference in results (the data have not been cited here). But a tone of $118 \mathrm{~dB}$, which was more intense than those used by Myers, among others, resulted in escape. We were surprised that it did not produce more dramatic results and that relatively few responses occurred within the 2-sec criterion adopted. This result did not change much even after tone and shock had been consistently paired. Shock presumably overshadows tone so that the pairing procedure would not be expected to produce a difference.

One reason for this experiment was to demonstrate that the use of a relatively medium-intensity tone as a signal for a known aversive event, like shock, meets the requirement of a so-called neutral stimulus, that is, a stimulus which on its own is unlikely to result in the kind of response most of ten used in studies of variables affecting aversive control. In this we have succeeded. The question whether escape from more intense tones, like the $118 \mathrm{~dB}$ used here, is attributable to an unconditioned startle response has not been investigated. There is some evidence that this may be so: Davis and Burton (1974) demonstrated that in an escape leverpressing situation rat subjects continuously engage the lever and that their escape behavior is attributable to a reflexive lurch produced by shock onset. Presumably, this mechanism could also operate when sudden intense stimuli other than shock are presented while the subject is holding the lever down. Such evidence would not support the notion that intense tone is an aversive event that underlies escape behavior. The issue can only be resolved by using an experimental situation in which startle is excluded as an operant for escape.

\section{REFERENCES}

Davis, H., \& Burton, J. The measurement of response force during a lever press shock escape procedure in rats. Journal of the Experimental Analysis of Behavior, 1974, 22, 433-440.

Hurwitz, H. M. B., \& Roberts, A. E. Aversively controlled behavior and the analysis of conditioned suppression. In $\mathrm{H}$. Davis \& H. M. B. Hurwitz (Eds.), Operant-Pavlovian interactions. Hillsdale, N.J: Erlbaum, 1977.

MYERS, A. K. Avoidance learning as a function of several training conditions and strain differences in rats. Journal of Comparative and Physiological Psychology, 1959, 52, 381-386.

Myers, A. K. Instrumental escape conditioning to low-intensity noise by rats. Journal of Comparative and Physiological Psychology, 1965, 60, 82-87.

Myers, A. K. Contradictory evidence from aversion to auditory stimuli resulting from different test methods. Journal of Comparative and Physiological Psychology, 1967, 64, 171-175.

(Received for publication March 8, 1980.) 